Research Article

\title{
In Vitro Efficacy Studies for Evaluating the Activity of a Self-assembled Nanoemulsion Formulation of Paclitaxel on Breast and Ovarian Cancer Cells
}

\author{
Mukta Bagul, Srikanth Kakumanu, Thomas A. Wilson \\ Center for Health and Disease Research - Division of NanoMedicine, Department of Clinical Laboratory and Nutritional Sciences \\ and the Biomedical Engineering/Biotechnology Ph.D. Program, University of Massachusetts Lowell, Lowell, MA 01854
}

Corresponding author: E-mail: Thomas_Wilson@uml.edu

Received: March 20, 2014; Accepted: Sept. 18, 2014; Published: Sept. 21, 2014.

Citation: Mukta Bagul, Srikanth Kakumanu, and Thomas A. Wilson. In Vitro Efficacy Studies for Evaluating the Activity of a Self-assembled Nanoemulsion Formulation of Paclitaxel on Breast and Ovarian Cancer Cells. Eng. 20I4, 6(3), 67-75.

DOI: $10.5101 /$ nbe.v6i3.p67-75.

\begin{abstract}
The drug of choice for treating breast and ovarian cancers is usually paclitaxel. This study was designed to evaluate the efficacy of a self-assembled nanoemulsion (SANE) of paclitaxel (NFP) on human breast (MCF-7) and ovarian (OVCAR-3) cancer cell lines. Cells were treated with various doses (1.2 $\mathrm{nM}-1200 \mathrm{nM}$ of paclitaxel) as the NFP or suspended in DMSO (PSD). While both significantly inhibited cell proliferation of MCF-7 at doses $>40 \mathrm{nM}$, at $12 \mathrm{nM}$ the NFP significantly inhibited cell proliferation $(-57 \%$; $p<0.05)$ greater than the PSD $(-5 \%)$. With OVCAR-3 cells, doses $>12 \mathrm{nM}$ for both significantly inhibited cell proliferation, but at $4 \mathrm{nM}$, the NFP significantly inhibited cell proliferation $(-60 \% ; \mathrm{p}<0.05)$ greater than the PSD $(-23 \%)$. These results demonstrate that the effect of NFP on the cell proliferation of MCF-7 and OVCAR-3 cells are significantly greater at a lower dose than the PSD and that the NFP exhibited similar mode of action by induction of apoptosis and cell cycle arrest as the PSD. Therefore a SANE formulation of Paclitaxel has the potential to be a promising delivery system for anti-cancer drugs.
\end{abstract}

Keywords: Nanoemulsion; Paclitaxel; Breast cancer cell line; Ovarian cancer cell line; Apoptosis

\section{Introduction}

Among cancer in women, breast cancer is one of the most frequently diagnosed [1-3]. However, along with breast cancer, ovarian cancer continues to be a challenge to treat despite many advances in anti-cancer drug therapy over the recent years $[4,5]$. Taxanes, such as paclitaxel and docetaxel, are routinely used as chemotherapeutic agents in treating both breast and ovarian cancer [6]. Anti-cancer drugs are known for non-specific distribution in the body where they affect tumor, as well as, normal cells, thereby leading to significant complications and side effects, such as sub-optimal treatment, resulting in excessive toxicity $[7,8]$. Paclitaxel is active across a broad spectrum of cancers but most especially against breast, ovarian, head and neck, and lung cancer [9, 10]. Several studies have confirmed the potent anti-tumor effects of paclitaxel, a microtubular inhibitor of cancer cells, by causing cell cycle arrest at G1 or G2/M that leads to double stranded DNA breaks leading to apoptosis and cell death $[11,12]$. Traditionally, paclitaxel is 
used as a single agent or in combination with other chemotherapeutic agents $[10,13]$.

Paclitaxel is known for its hydrophobic properties, which results in the use of solubilizers to aid its administration [8, 14]. Conventionally, formulation vehicles such as Cremophor EL and ethanol are used for paclitaxel administration [10]. However, severe side effects are also associated with these vehicles, which limit the amount of drug that can be safely administered [15-17]. Although the paclitaxel regimen is one of the most effective in treating cancer, it is associated with non-specific toxicity [18]. There is a great need in the area of therapeutic agents used in the treatment of cancer to develop alternative delivery system, which can increase their therapeutic efficacy (either through increase bioavailability or delivery to tumor cells) while at the same time decreasing their toxicity (usually through decrease dose). This will lead to minimal side effects such as neurotoxicity and hypersensitivity usually caused by the vehicles delivering the agent or the necessity of using higher doses [19].

Recent advances in nanotechnology formulation has lead to exciting opportunities for specific drug delivery systems that will help overcome drug solubility issues $[20,21]$. Over the past few years, our laboratory has utilized microfluidization [22] and self-assembled nanoemulsions (SANE) [23, 24] [patents pending] to study enhanced drug and nutrient delivery systems and efficacy in various in vitro and in vivo models. Nanoemulsions are a class of stable emulsions formed by monolayers of phospholipids composed of a surfactant and oil suspended in water. The nanoemulsions are often referred to as "Approaching Thermodynamic Stability" [25, 26]. Compared to typical suspension preparations which can be thousands of nanometers in size, nanoemulsion delivery systems utilized and reported from our lab, as well as those of others, with particle sizes approximately $100 \mathrm{~nm}$ or less have been shown to increase bioavailability and efficacy in vivo of delta and gamma tocopherol, aspirin, an antioxidant synergy formulation (ASF), and dacarbazine [22, 24, 26,].

Taking into consideration the issues related to paclitaxel delivery and its vehicles, developing a nanotechnology-based formulation for drug delivery which could still maintain the efficacy of paclitaxel and increase the specificity of the drug would be ideal. Additionally, if a blank nanoformulation (contains no drug) would exhibit no or minimal activity against cells, especially normal cells, then these nanoemulsions could be a strong alternative drug delivery system. The SANE formulation of paclitaxel was well characterized in our previous report [27]. The present investigation was undertaken to evaluate the biological activity of paclitaxel encapsulated utilizing our SANE formulation on cell proliferation, cell cycle arrest, and apoptotic activity on a human breast cancer and ovarian cancer cell lines.

\section{Methods}

\section{Cell culture lines, growth conditions, and reagents}

The human breast cancer cell line, MCF-7, and ovarian cancer cell line, OVCAR-3, were purchased from American Type Culture Collection (ATCC, Manassas, VA). These human cultured tumor cell lines were propagated at $37^{\circ} \mathrm{C}$ in $5 \% \mathrm{CO}_{2} / 95 \% \mathrm{O}_{2}$ using ATCC-formulated RPMI-1640 Medium and 10\% (v/v) fetal bovine serum (FBS).

\section{Nanoemulsion and suspension formulations}

The SANE formulation (NFP) was made by dissolving 9 milligrams of paclitaxel (Sigma Aldrich, St Louis, MO) in two grams of rice bran oil (Tsuno, Japan) in a beaker heated @ $50-60^{\circ} \mathrm{C}$ and stirred for 5 min using a magnetic stirrer. Four grams of Solutol HS was added, the mixture was heated and stirred again for $5 \mathrm{~min}$ at $60^{\circ} \mathrm{C}$ until the three components formed a homogeneous mixture. Distilled water was added to a final volume of $25 \mathrm{~mL}$ while the mixture was stirred at $60^{\circ} \mathrm{C}$. During heating, when the phase inversion zone (PIT or HLB) temperature of the system is reached $\left(65-70^{\circ} \mathrm{C}\right)$, the surfactant is in equilibrium with the oil and water phases. Heating and stirring was then continued beyond the PIT up to $80^{\circ} \mathrm{C}$. At this temperature the system is inverted into a waterin-oil emulsion. The emulsion was then cooled to room temperature to obtain an oil-in-water emulsion. A blank nanoemulsion was also formulated the same way except no paclitaxel was added to the rice bran oil. The suspension (PSD) was made by dissolving the same amount of paclitaxel in DMSO. To make the various doses of NFP and PSD, the original stock formulations of each were serial diluted into the cell culture media prior to each experiment. 


\section{Particle size, morphology and encapsulation of formulations}

The viscosity of the PSD and NFP stock formulations were measured using an Ubbelohde Viscometer (VWR International, Boston MA, USA) at $25^{\circ} \mathrm{C}$. For measurement of the mean droplet size and polydispersity index (width of the particle size distribution) a dynamic laser light scattering Malvern Zetasizer Nanoseries Nano-ZS instrument (Malvern Instruments Inc. Southborough, MA, USA) was used. Transmission electron microscope (TEM) (Philips EM400T) was performed in order to observe the morphology of nanoemulsion. The nanoemulsion was diluted in the ratio of 1:200 with distill ionized water and one drop of the dilution was taken and placed into the carbon attached Vinylec Films (Ernest F. Fullam, Inc. Latham NY). The excess liquid was removed with filter paper and the film was allowed to stand for $10 \mathrm{~min}$. After, the grid was stained with $10 \%$ phosphotungstic acid (Sigma Aldrich, St Louis MO) and allowed to dry for $5 \mathrm{~min}$. The sample was then placed in the vacuum chambers for $30 \mathrm{~min}$ before TEM analysis.

Paclitaxel was analyzed by HPLC (Agilent 1100 series, Santa Clara, California, USA), composed of a G1311A quaternary pump, G1313A autosampler, G1322A vacuum degasser, solvent module, HP Chemstation and computer control, a G1315A diode array detector using a reverse phase Zorbax C18 column $(250 \times 4 \mathrm{~mm}, 5 \mathrm{um})$ at room temperature. The detector was set at $227 \mathrm{~nm}$ and injection volume was $20 \mu \mathrm{L}$. The mobile phase was a mixture of acetonitrile and water $(50: 50 \mathrm{v} / \mathrm{v})$ at flow rate of $1 \mathrm{ml} / \mathrm{min}$. Both the PSD and the NFP were originally diluted in $1 \mathrm{~mL}$ of acetonitrile and then further dilutions were made using the mobile phase.

\section{In Vitro cytoxicity assay}

Cell number and proliferation were assessed using MTS reagent (Promega Corporation, Madison, Wisconsin USA), according to the manufacturer's instructions. Cultured cells were plated at a density of 5000 cells per well into 96 -well, flat-bottomed tissue culture plates and cultured overnight at $37^{\circ} \mathrm{C}$ in $5 \%$ $\mathrm{CO}_{2} / 95 \% \mathrm{O}_{2}$. MCF-7 cells and OVCAR- 3 cells were each treated with $1.2 \mathrm{nM}, 4 \mathrm{nM}, 12 \mathrm{nM}, 40 \mathrm{nM}, 120$ $\mathrm{nM}, 400 \mathrm{nM}$, or 1,200 nM, of paclitaxel as the NFP or PSD. Untreated cells and a blank nanoemulsion were used as controls. After $72 \mathrm{hr}$ incubation, MTS reagent was added, incubated for an additional $2 \mathrm{hr}$, and then the cell plates were measured at a wavelength of 490 $\mathrm{nm}$ using SpectraMAX microplate reader (Molecular Devices, Sunnyvale, California). Cell inhibition was calculated using the following equation: Cell Inhibition $(\%)=\left(1-\left(\mathrm{Abs}_{\mathrm{s}} / \mathrm{Abs}_{\mathrm{ctrl}}\right)\right) * 100$ where $\mathrm{Abs}_{\mathrm{s}}$ is the absorbance of the cells tested with the NFP, PSD, or blank nanoemulsion formulations and $\mathrm{Abs}_{\text {ctrl }}$ is the absorbance of untreated cells.

\section{Cell cycle}

Briefly, MCF-7 and OVCAR-3 cells were seeded $2 \times 10^{5}$ cells per well into a six-well plate. The next day, cells were treated with $1.2 \mu \mathrm{M}$ of paclitaxel as either NFP or PSD for $48 \mathrm{hr}$. Untreated cells and cells treated with the blank nanoemulsion were used as controls. After treatment, the cells were washed with PBS, trypsinized and fixed in cold ethanol for 2 hr. Cells were then washed and resuspended in PBS + $100 \mu \mathrm{g} / \mathrm{mL}$ of propidium iodide (Invitrogen, Carlsbad CA) and $40 \mu \mathrm{g} / \mathrm{mL}$ RNase A (Sigma Aldrich, St Louis, $\mathrm{MO}$ ) for $30 \mathrm{~min}$ in a dark at room temperature. Cells were run on a Flow Cytometer (BD Biosciences, San Jose California). When bound to cellular nucleic acid, propidium iodide has an excitation maximum at 535 $\mathrm{nm}$ and emission at $617 \mathrm{~nm}$. Cell populations were analyzed using Modfit LT 3.0 software to determine percentages of cells in $\mathrm{G} 1$ or G2/M phase.

\section{Caspase-Glo ${ }^{\circledR} 3 / 7$ activity assay}

Caspase-Glo ${ }^{\circledR}$ 3/7 assay kit (Promega, Madison, WI) was used to measure caspase activity. This assay detects caspase- 3 and caspase- 7 activity, which are used as an indication of apoptosis. The caspase $3 / 7$ activity is measured by addition of luminogenic caspase- $3 / 7$ substrate, which is cleaved by the enzymes caspase-3/7 to release a substrate for luciferase resulting in the luciferase reaction. Briefly, OVCAR-3 cells ( 4000 cells per well) were seeded in white bottom tissue culture treated 96-well plate and incubated for 24 $\mathrm{hr}$ at $37^{\circ} \mathrm{C}$ in $5 \% \mathrm{CO}_{2} / 95 \% \mathrm{O}_{2}$. After $24 \mathrm{hr}$, OVCAR-3 cells were treated with $40 \mathrm{nM}, 120 \mathrm{NM}, 400 \mathrm{nM}$, or $1200 \mathrm{nM}$ of paclitaxel as the NFP or PSD and further incubated for $24 \mathrm{hr}, 48 \mathrm{hr}$ or $72 \mathrm{hr}$. Untreated cells and cells treated with the blank nanoemulsion were used as controls. One hundred $\mu \mathrm{L}$ of caspase- $3 / 7$ reagent was added to each well and incubated for $1 \mathrm{hr}$ in the dark at room temperature. Luminescence for each well was recorded to measure caspase-3/7 activity. 


\section{Statistical analysis}

SigmaStat software was used for all statistical evaluations (Jandel Scientific, San Rafael, CA, USA). Either a one-way analysis of variance (ANOVA) or repeated measures (RM) ANOVA was used to analyze the data. When statistical significance was found by ANOVA, the Student-Newman-Keuls separation of means was used to determine treatment differences. All values are expressed as mean \pm SD. Statistical significance was set at the minimum $p<0.05$. Three separate experiments were carried out each in triplicate for each measurement.

\section{Results}

\section{NFP and PSD formulation characteristics}

The NFP stock formulation of paclitaxel exhibited a particle size of $20 \mathrm{~nm}$, a zeta potential of $1 \mathrm{mV}$, and a polydiversity index (PDI) of 0.1 . The particle size of the stock PSD formulation was greater than the capability of the instrument to measure $(>6 \mu \mathrm{m})$. Since the stock formulations of the NFP and PSD were diluted with cell culture media with the cells; particle sizes, zeta potentials, and PDI were not measured for each of the doses of NFP and PSD. In addition, the morphology of the PSD was characterized by TEM analysis and the particle size was approximately the same as hydrodynamic diameter measured by the light scattering instrument. TEM images also indicated that the NFP nanoemulsions were evenly distributed and spherical in shape. TEM was not performed on the PSD since it was a suspension of paclitaxel in DMSO and the particle sizes were very large. The encapsulation efficiency of paclitaxel in the PSD was approximately $87 \%$. Since the PSD does not form emulsions, no encapsulation efficiency was performed.

\section{Effect of NFP and PSD on cell proliferation of MCF-7 and OVCAR-3 cells}

While both the NFP and PSD significantly inhibited cell proliferation of MCF-7 similarly $(-60 \%$; $<0.05)$ at doses between 40-1200 nM of paclitaxel, $12 \mathrm{nM}$ of paclitaxel as the NFP significantly inhibited cell proliferation $(-57 \%$; $<<0.05)$ greater than the PSD ( $-5 \%$; not significant) relative to untreated or blank nanoemulsion-treated cells (Figure 1(a)). At doses of 4 and $1.2 \mathrm{nM}$ of paclitaxel as the NFP and PSD, a non-significant change in percent inhibition of cell

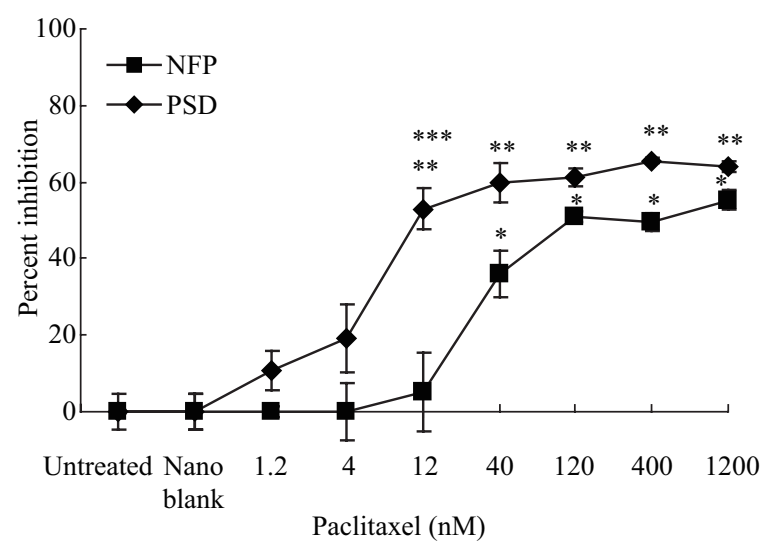

(a)

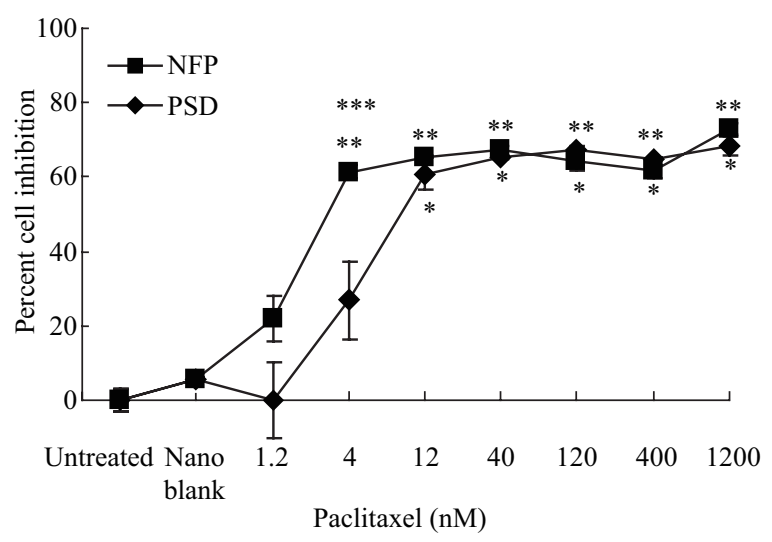

(b)

Fig. 1 (a) Percent inhibition of cell proliferation of MCF7 cells after $72 \mathrm{hr}$ of treatment. Data is expressed as mean \pm SD of three independent experiments performed in triplicate. * Represents a significant difference at $\mathrm{p}<0.05$ when PSD treated cells are compared to untreated cells. ${ }^{* *}$ Represents a significant difference at $\mathrm{p}<0.05$ when NFP treated cells are compared to untreated cells. $* * *$ Represents a significant difference at $\mathrm{p}<$ 0.05 between NFP and PSD at $12 \mathrm{nM}$ of Paclitaxel; (b) Percent inhibition of cell proliferation of OVCAR-3 cells after $72 \mathrm{hr}$ of treatment. Data is expressed as mean $\pm \mathrm{SD}$ of three independent experiments performed in triplicate. * Represents a significant difference at $p<0.05$ when PSD treated cells are compared to untreated cells. $* *$ Represents a significant difference at $\mathrm{p}<0.05$ when NFP treated cells are compared to untreated cells. $* * *$ Represents a significant difference at $\mathrm{p}<0.05$ between NFP and PSD at $4 \mathrm{nM}$ of Paclitaxel.

proliferation of MCF-7 was observed compared to controls (Figure 1(a)). Untreated cells and the blank nanoemulsion-treated cells were not different from each other for percent inhibition of cell proliferation of MCF-7. An IC50 value of $12 \mathrm{nM}$ of paclitaxel was calculated when the MCF-7 cells were treated with the NFP formulation as compared to $110 \mathrm{nM}$ of paclitaxel when the MCF-7 cells were treated with the PSD formulation.

Similar results were observed with OVCAR-3 cells where at doses between 12-1,200 nM of paclitaxel, both the NFP and PSD formulations 
significantly inhibited cell proliferation $(-60 \% ; \mathrm{p}<$ 0.05 ), but at a dose of $4 \mathrm{nM}$ of paclitaxel, the NFP formulation significantly inhibited cell proliferation $(-60 \% ; \mathrm{p}<0.05)$ greater than the PSD formulation $(-26 \%$; not significant) relative to untreated and blank nanoemulsion-treated cells (Figure 1(b)). At dose of $1.2 \mathrm{nM}$ of paclitaxel as the NFP and PSD, a non-significant change in percent inhibition of cell proliferation of OVCAR-3 cells was observed compared to controls (Figure 1(b)). Untreated cells and cells treated with the blank nanoemulsion were not different for cell inhibition of cell proliferation. A comparable IC50 value was calculated of $2 \mathrm{nM}$ and 9 $\mathrm{nM}$ of Paclitaxel when OVCAR-3 cells were treated with NFP and PSD respectively.

\section{Activation of Caspase 3/7}

The induction of apoptosis was studied by looking at the activation of caspase-3/7 with NFP- and PSDtreated OVCAR-3 cells. A consistent two-fold significant increase $(\mathrm{p}<0.05)$ in caspase-3/7 activation was observed between OVCAR-3 cells treated with 1,200 $\mathrm{nM}$ of paclitaxel as the NFP or PSD when compared with untreated or blank nanoemulsiontreated cells after treatment for $48 \mathrm{hr}$ (Figure 2). OVCAR-3 cells demonstrated maximum activation of caspase-3/7 at both $48 \mathrm{hr}$ and $72 \mathrm{hr}$ of treatment as compared to $24 \mathrm{hr}$ when treated with $1,200 \mathrm{nM}$ of paclitaxel as the NFP and PSD (Figure 2). After $72 \mathrm{hr}$ treatment with NFP and PSD a significant activation ( $p$ $<0.05$ ) of caspase-3/7 was observed when OVCAR-3 cells were treated with doses of $4 \mathrm{nM}, 12 \mathrm{nM}, 40 \mathrm{nM}$, $120 \mathrm{nM}, 400 \mathrm{nM}$, and 1,200 nM of paclitaxel compared to controls (Figure 2). There was no indication of caspase-3/7 activation in untreated cells, cells treated

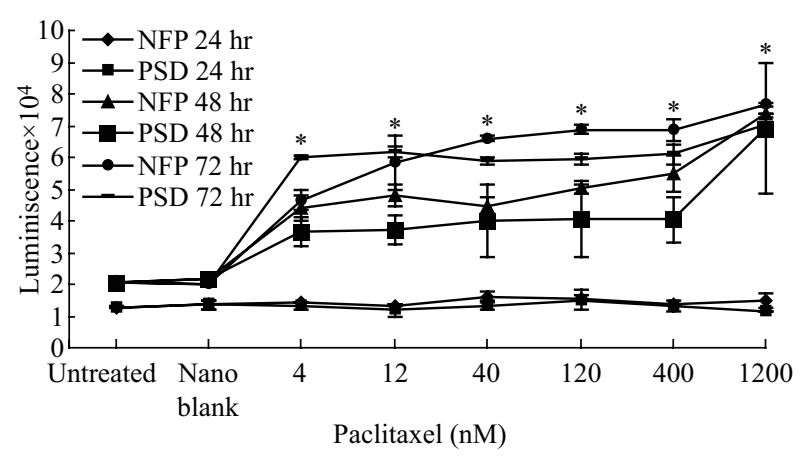

Fig. 2 Caspase-3/7 activity on OVCAR-3 cells after 24, 48, and $72 \mathrm{hr}$ of treatment. Data is expressed as mean $\pm \mathrm{SD}$ of three independent experiments performed in triplicate. * Represents a significant difference at $p<0.05$ when NFP and PSD treated cells are compared to untreated cells. with the blank nanoemulsion, or treated with any dose of paclitaxel as the NFP or PSD after $24 \mathrm{hr}$ of treatment (Figure 2).

\section{Cell cycle analysis}

To determine whether the growth inhibitory effects of NFP were cell cycle dependent, flow cytometric studies were conducted. MCF-7 and OVCAR-3 cells were exposed to $1,200 \mathrm{nM}$ of paclitaxel as the NFP and PSD for $48 \mathrm{hr}$ and cell number arrest in each phase of the cell cycle; G1, G2, and S phase, was examined. Treatment of MCF-7 cells with 1,200 nM of paclitaxel as the NFP $(66 \%$; p < 0.05$)$ or the PSD $(94.05 \%$; $p$ $<0.05)$ resulted in $\mathrm{G} 2 / \mathrm{M}$ cell cycle arrest compared to untreated cells, which demonstrated a G2/M arrest of $20 \%$ for the nanoemulsion blank-treated cells and untreated cells, respectively (Figure 3(a)). The NFP and PSD were not significantly different from each other (Figure 3(a)).

Treatment with $1,200 \mathrm{nM}$ of paclitaxel as the NFP on OVCAR-3 cells resulted in 93\% ( $<$ < 0.05) G2/ $\mathrm{M}$ cell cycle arrest. This is similar to the treatment of OVCAR-3 cells at the same dose of paclitaxel as the PSD, which resulted in $96 \%(\mathrm{p}<0.05) \mathrm{G} 2 / \mathrm{M}$ cell cycle arrest compared to untreated cells, which demonstrated $23.54 \%$ and $25.5 \%$ G2/M cell cycle arrest with the nanoemulsion blank-treated cells and untreated cells, respectively (Figure 3(b)). The NFP and PSD were not significantly different from each other (Figure 3(b)).

\section{Discussion}

Traditionally, chemotherapeutic drugs for cancer treatment are administered through oral, intravenous, or intramuscular routes. Paclitaxel is a chemotherapeutic drug with significant anti-tumor activity and is used alone or in combination for treatment of breast, ovarian, and head and neck cancer $[10,13,28]$. Paclitaxel is however very hydrophobic and is traditionally formulated in the castor oil derived solvent, Cremophor EL, and ethanol. Cremophor EL is associated with toxicity and some acute hypersensitive reactions such as flushing, rash, chest pain and tachycardia [17]. Additionally, it is also known to form micelles in aqueous solution which in turn leads to ineffective administration of paclitaxel to the tumor [17, 29, 30]. In recent years paclitaxel has been delivered in an albumin bound formulation (Abraxane ${ }^{\circledR}$ ) used in breast cancer treatment [31]. Over the years, many 
MCF7

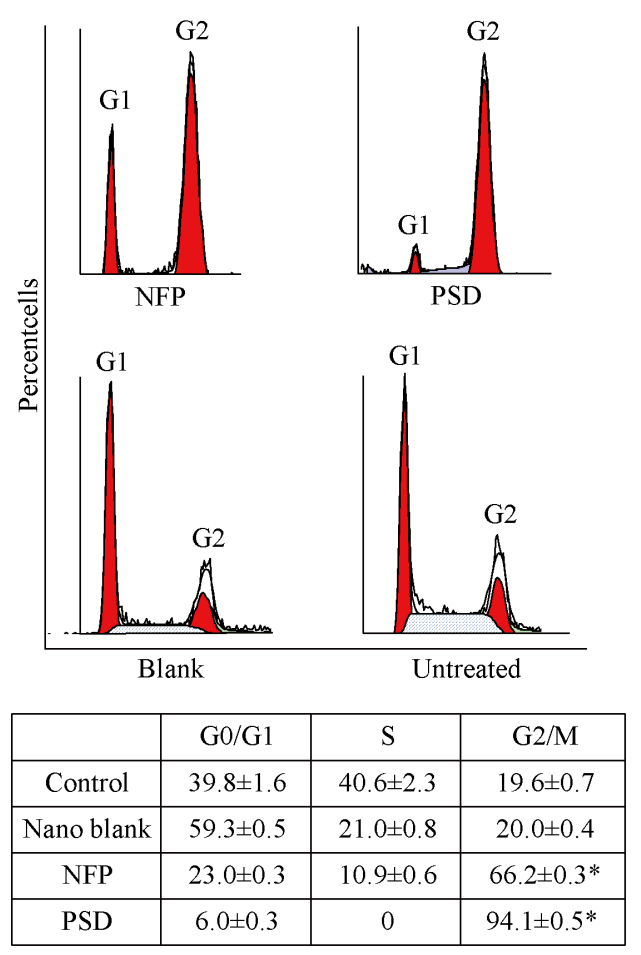

(a)

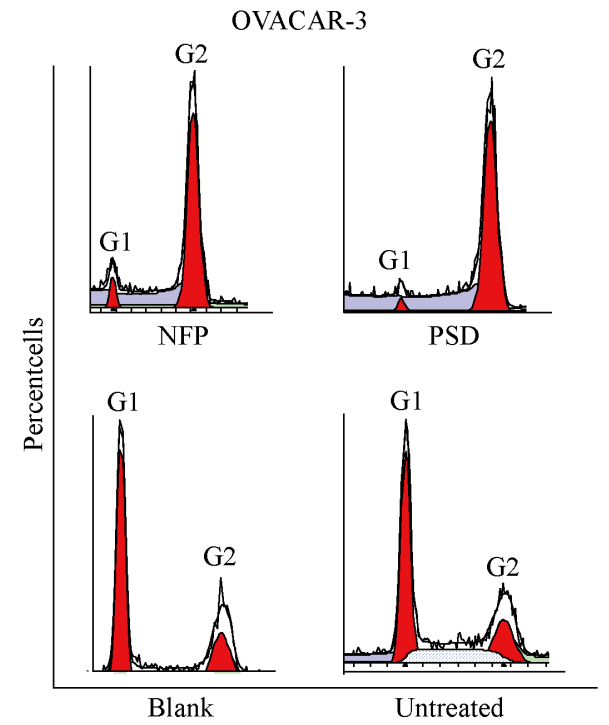

\begin{tabular}{|c|c|c|c|}
\hline & G0/G1 & S & G2/M \\
\hline Control & $53.0 \pm 2.9$ & $25.5 \pm 1.8$ & $21.5 \pm 0.6$ \\
\hline Nano blank & $58.2 \pm 0.5$ & $18.3 \pm 0.4$ & $23.5 \pm 0.8$ \\
\hline NFP & $7.3 \pm 0.7$ & 0 & $92.7 \pm 2.3^{*}$ \\
\hline PSD & $3.4 \pm 0.3$ & 0 & $96.0 \pm 4.5^{*}$ \\
\hline
\end{tabular}

(b)

Fig. 3 Percent cell cycle phase distribution of MCF-7 (a) and OVCAR-3 (b) after $48 \mathrm{hr}$ of treatment. The data is expressed is mean $\pm \mathrm{SD}$ of three independent experiments performed in triplicate. * Represents a significant difference at $\mathrm{p}<0.05$ when cells treated with NFP and PSD are compared to untreated cells.

investigators have been trying to develop paclitaxel nanoformulations that retain the anti-tumor properties of paclitaxel but reduce the non-specific toxicity related to the vehicles in which paclitaxel is delivered [32-35]. Many studies have shown that nanotechnology has a great potential not only to improve the characteristics of drugs that are hydrophobic and require the use of toxic solvents for delivery, but also increases the specificity of drugs by increasing the delivery of the drug to the targeted sites [20, 36-39].

Even though the drug is stabilized and protected in the nanoemulsion, due to unfavorable conditions of the formulation, the encapsulated drug can lose its integrity, which in turn leads to decreased biological activity [40]. The success of a drug delivery system depends not only on retaining the biological activity of the encapsulated drug but also enhancing its efficacy at lower doses, maintaining the potency of the drug even after encapsulation into a nanoemulsion system relative to its suspension form, and exhibiting the same mode of action as its suspension form. The efficacy of the nanoemulsion formulation of an anti-cancer drug, such as paclitaxel, would be measured by its cytotoxic activity, apoptotic activities, and cell cycle arrest on cancer cells after formulation.

In this study, we investigated the anti-proliferative effects of a self-assembled nanoemulsion formulation (NFP) of paclitaxel having a particle size of $20 \mathrm{~nm}$ and zeta potential of $1 \mathrm{mV}$ on a human breast cancer, MCF7, and a human ovarian cancer, OVCAR-3, cell lines compared a suspension of paclitaxel in DMSO (PSD). Treatment with NFP and PSD induced substantial growth inhibition in both the breast cancer and ovarian cancer cell lines. However, treatment with NFP at 12 $\mathrm{nM}$ of paclitaxel in MCF-7 and at $4 \mathrm{nM}$ in OVCAR-3 cells induced a 9-fold and 3-fold greater inhibitory effect than the cells treated with the same doses of paclitaxel as the PSD indicating that a lesser amount of the drug may be needed to induce similar or better antiproliferative effects when the drug is encapsulated as a nanoemulsion. Importantly, a blank nanoemulsion had no effect on MCF-7 and OVCAR-3 cells, suggesting that NFP induces selective growth inhibitory effects in MCF-7 and OVCAR-3 cells due to the presence of paclitaxel. Therefore NFP inhibits cell proliferation by lowering the minimal effective dose required for cancer treatment. It is possible that the NFP has greater efficacy than the PSD at these lower doses 
because more paclitaxel is being delivered into the cell through the NFP nanoemulsion due to either smaller particle size and/or greater stability of the drug as a nanoemulsion or for some other unknown mechanism. It is important to note, that at higher doses, both the NFP and PSD showed similar cytotoxic effects on both cell lines. These results are similar to previous work by our laboratory $(25,26)$ with the chemotherapeutic drugs dacarbazine and tamoxifen, which also showed greater efficacy when utilized as a nanoemulsion formulation as compared to their suspension formulations in both a MCF-7 cancer cell line and a xenograft mouse model of melanoma.

To further elucidate the mechanisms of enhanced cytotoxicity by NFP, we studied the apoptotic effects of NFP and PSD on OVCAR-3 cells. Apoptosis is associated with various proteins, including caspase-3 and -7 , which are essential downstream effector caspases involved in this pathway [41, 42]. Caspase -3 and -7 are responsible for the morphological and biochemical changes that are typical characteristics of apoptotic cell death [41]. Therefore, caspase-3 and -7 activation are a common means to study the apoptosis pathway in various cell lines. Previous work [43] has demonstrated that MCF-7 does not express caspase- 3 activity and hence, in this study we assessed the activation of caspase- 3 and -7 after treatments only on OVCAR-3 cells. Both NFP and PSD at all doses of paclitaxel treatment of OVCAR-3 cells induced apoptosis at $48 \mathrm{hr}$ and were sustained at $72 \mathrm{hr}$. Thus, showing that a nanoemulsion of paclitaxel retains the same mode and amount of apoptotic activity as a suspension of paclitaxel and is similar to the apoptotic activity observed in previous studies [42, 44, 45]. No apoptotic activity was observed in cells treated with the blank nanoemulsion, confirming that the anti-cancer mechanism of the NFP is related to the presence of paclitaxel and not due to the other components of the nanoemulsion formulation.

This study also examined the effect of encapsulation of paclitaxel into the nanoemulsion on cell cycle arrest. Paclitaxel has previously been shown to arrest the cell cycle at the G1 or G2 phases followed by apoptosis [46]. Here, the percent number of cells in G1, G2, and $\mathrm{S}$ phases was measured following treatment with NFP and PSD at 1,200 nM of paclitaxel for $48 \mathrm{hr}$. This demonstrated that NFP treatment of MCF-7 and OVCAR-3 resulted in a marked increase of cells in G2 arrest that is similar to treatment with paclitaxel as the PSD. In contrast, cells treated with the blank nanoemulsion showed a 3-fold decrease in the number of cells in G2 arrest. Notably, the data showed similar results between the nanoemulsion formulation and suspension of paclitaxel, again suggesting the specificity of Paclitaxel presence in the nanoemulsion formulation.

\section{Conclusions}

This study provides evidence that a self-assembled nanoemulsion formulation of paclitaxel effectively inhibits cell growth of both breast and ovarian cancer cells at lower doses compared to a suspension of paclitaxel while inducing similar drug related apoptotic activity in ovarian cancer cells. Moreover, this selfassembled nanoemulsion formulation of paclitaxel triggers a significant $\mathrm{G} 2 / \mathrm{M}$ cell cycle arrest indicating that the anti-cancer activity is related to the inhibition of mitosis, which is a typical characteristic of paclitaxel induced cell proliferation inhibition. Therefore we speculate that this formulation has a potential for being a good drug delivery system for anti-cancer drugs such as paclitaxel. Further investigation of NFP treatment on in vivo cancer models is required for better understanding of therapeutic efficacy.

\section{Acknowledgments}

The authors are very thankful to Dr. Robert J. Nicolosi for his technical support and to Maureen Faul for her administrative support. All the authors agree that the contents of the paper are confidential and will not be copyrighted, submitted, or published elsewhere (including the Internet), in any language, while acceptance by the journal is under consideration. There is no any financial conflict of interests.

\section{References}

[1] Coughlin SS, Ekwueme DU. Breast cancer as a global health concern. Cancer Epidemiol. 2009, 33: 315-318.

[2] Smith RA, Cokkinides V, Brooks D, Saslow D, Brawley OW. Cancer screening in the United States, 2010: a review of current American Cancer Society guidelines and issues in cancer screening. Cancer J. Clin. 2010, 60: 99-119.

[3] Virnig BA, Tuttle TM, Shamliyan T, Kane RL. Ductal carcinoma in situ of the breast: a systematic review of incidence, treatment, and outcomes. J. Nat. Cancer Inst. 2010, 102: 170-178.

[4] Hennessy BT, Coleman RL, Markman M. Ovarian cancer. Lancet 2009, 374: 1371-1382.

[5] Foster T, Brown TM, Chang J, Menssen HD, Blieden MB, Herzog TJ. A review of the current evidence for maintenance therapy in ovarian cancer. Gynecol. Oncol. 2009, 115: 290-301. 
[6] Pazdur R, Kudelka AP, Kavanagh JJ, Cohen PR, Raber MN. The taxoids: paclitaxel (Taxol) and docetaxel (Taxotere). Cancer Treat. Rev. 1993, 19: 351-386.

[7] Rowinsky EK, Eisenhauer EA, Chaudhry V, Arbuck SG, Donehower RC. Clinical toxicities encountered with paclitaxel (Taxol). Sem. Oncol. 1993, 20: 1-15.

[8] Singla AK, Garg A, Aggarwal D. Paclitaxel and its formulations. Int. J. Pharm. 2002, 235: 179-192.

[9] Gradishar W, Cortes J. Clinical efficacy and emerging therapeutic utilization of novel taxanes. Eur. J. Cancer 2008, 6(Suppl 10): 12-21.

[10] Panchagnula R. Pharmaceutical aspects of paclitaxel. Int. J. Pharm. 1998, 172: 1-15.

[11] Wang J, He FT, Tzang CH, et al. Differential gene expression profiles in paclitaxel-induced cell cycle arrest and apoptosis in human breast cancer MCF-7 cells. Yao Xue Xue Bao = Acta Pharmacentica Sinica. 2005, 40: 1099-1104.

[12] Barboule N, Baldin V, Jozan S, Vidal S, Valett A. Increased level of p21 in human ovarian tumors is associated with increased expression of CDK2, cyclin A and PCNA. Int. J. Cancer 1998, 76: 891-896.

[13] Hortobagyi GN, Holmes FA. Single-agent paclitaxel for the treatment of breast cancer: an overview. Sem. Oncol. 1996, 23: 4-9.

[14] Yang T, Cui FD, Choi MK, et al. Liposome formulation of paclitaxel with enhanced solubility and stability. Drug Deliv. 2007, 14: 301-308.

[15] Sykes E, Woodburn K, Decker D, Kessel D. Effects of Cremophor EL on distribution of Taxol to serum lipoproteins. Brit. J. Cancer 1994, 70: 401-404.

[16] Sparreboom A, van Zuylen L, Brouwer E, et al. Cremophor EL-mediated alteration of paclitaxel distribution in human blood: clinical pharmacokinetic implications. Cancer Res. 1999, 59: 1454-1457.

[17] Gelderblom H, Verweij J, van Zomeren DM, et al. Influence of Cremophor El on the bioavailability of intraperitoneal paclitaxel. Clin. Cancer Res. 2002, 8: 1237-1241.

[18] Kita T, Kikuchi Y, Takano M, et al. The effect of single weekly paclitaxel in heavily pretreated patients with recurrent or persistent advanced ovarian cancer. Gynecol. Oncol. 2004, 92: 813-818.

[19] Kaur T, Slavcev RA, Wettig SD. Addressing the challenge: current and future directions in ovarian cancer therapy. Cur. Gene Ther. 2009, 9: 434-458.

[20] Gaumet M, Vargas A, Gurny R, Delie F. Nanoparticles for drug delivery: The need for precision in reporting particle size parameters. Eur. J. Pharm. Biopharm. 2008, 69: 1-9.

[21] Bawarski WE, Chidlowsky E, Bharali DJ, Mousa SA. Emerging nanopharmaceuticals. Nanomedicine 2008, 4: 273-282.

[22] Kuo F, Subramanian B, Kotyla T, Wilson TA, Yoganathan S, Nicolosi RJ. Nanoemulsions of an anti-oxidant synergy formulation containing gamma tocopherol have enhanced bioavailability and anti-inflammatory properties. Int. J. Pharm. 2008, 363: 206-213.

[23] Kotyla T, Kuo F, Moolchandani V, Wilson TA, Nicolosi RJ. Increased bioavailability of a transdermal application of a nano-sized emulsion preparation. Int. J. Pharm 2008, 347: 144-148.

[24] Subramanian B, Kuo F, Ada E, et al. Enhancement of anti-inflammatory property of aspirin in mice by a nanoemulsion preparation. Int. Immunopharm. 2008, 8: 15331539.

[25] Tagne JB, Kakumanu S, Nicolosi RJ. Nanoemulsion Preparations of the Anticancer Drug Dacarbazine Significantly Increase Its Efficacy in a Xenograft Mouse Melanoma Model. Mol. Pharm. 2008, 5: 1055-1063.

[26] Tagne JB, Kakumanu S, Ortiz D, Shea T, Nicolosi RJ.
A nanoemulsion formulation of tamoxifen increases its efficacy in a breast cancer cell line. Mol. Pharm. 2008, 5: 280-286.

[27] Bagul M, Kakumanu S, Wilson TA, Nicolosi RJ. In Vitro Evaluation of Antiproliferative Effects of Self-Assembling Nanoemulsion Of Paclitaxel On Various Cancer Cell Lines. Nano Biomed. Eng. 2010, 2: 100-108.

[28] Hortobagyi GN, Holmes FA, Theriault RL, Buzdar AU. Use of Taxol (paclitaxel) in breast cancer. Oncol. 1994, 51(Suppl 1): 29-32.

[29] Gelderblom H, Verweij J, Nooter K, Sparreboom A. Cremophor EL: the drawbacks and advantages of vehicle selection for drug formulation. Eur. J. Cancer. 2001, 37: 1590-1598.

[30] Nornoo AO, Osborne DW, Chow DS. Cremophor-free intravenous microemulsions for paclitaxel I: formulation, cytotoxicity and hemolysis. Int. J. Pharm. 2008, 349: 108-116.

[31] Feng Z, Zhao G, Yu L, Gough D, Howell SB. Preclinical efficacy studies of a novel nanoparticle-based formulation of paclitaxel that out-performs Abraxane. Cancer Chemother. Pharmacol. 2010, 65: 923-930.

[32] Luo C, Wang Y, Chen Q, Han X, Liu X, Sun J, He Z. Advances of paclitaxel formulations based on nanosystem delivery technology. Mini Rev. Med. Chem. 2012, 12: 434-444.

[33] Bhardwaj V, Ankola DD, Gupta SC, Schneider M, Lehr CM, Kumar MN. PLGA nanoparticles stabilized with cationic surfactant: safety studies and application in oral delivery of paclitaxel to treat chemical-induced breast cancer in rat. Pharm. Res. 2009, 26: 2495-2503.

[34] Yang Y, Wang Z, Li M, Lu S. Chitosan/pshRNA Plasmid Nanoparticles Targeting MDR1 Gene Reverse Paclitaxel Resistance in Ovarian Cancer Cells. J. Huazhong University Sci. Technol. (Medical Sciences). 2009, 29: 239-242.

[35] Tan Q, Liu X, Fu X, Li Q, Dou J, Zhai G. Current development in nanoformulations of docetaxel. Expert Opin. Drug Deliv. 2012, 9: 975-990.

[36] Haq AI, Zabkiewicz C, Grange P, Arya M. Impact of nanotechnology in breast cancer. Exp. Rev. Anticancer Ther. 2009, 9: 1021-1024.

[37] Hawkins MJ, Soon-Shiong P, Desai N. Protein nanoparticles as drug carriers in clinical medicine. $A d v$. Drug Del. Rev. 2008, 60: 876-885.

[38] Brannon-Peppas L, Blanchette JO. Nanoparticle and targeted systems for cancer therapy. Adv. Drug Del. Rev. 2004, 56: 1649-1659.

[39] Shahin M, Lavasanifar A. Novel self-associating poly(ethylene oxide)-b-poly(var epsilon-caprolactone) based drug conjugates and nano-containers for paclitaxel delivery. Int. J. Pharm. 2010, 389: 213-222.

[40] Chen H, Khemtong C, Yang X, Chang X, Gao J. Nanonization strategies for poorly water-soluble drugs. Drug Dis. Today. 2011, 16: 354-360.

[41] Janicke RU, Sprengart ML, Wati MR, Porter AG. Caspase- 3 is required for DNA fragmentation and morphological changes associated with apoptosis. J. Biol. Chem. 1998, 273: 9357-9360.

[42] Saunders DE, Lawrence WD, Christensen C, Wappler NL, Ruan H, Deppe G. Paclitaxel-induced apoptosis in MCF7 breast-cancer cells. Int. J. Cancer. 1997, 70: 214-220.

[43] Janicke RU. MCF-7 breast carcinoma cells do not express caspase-3. Breast Cancer Res. Treat., 2009, 117: 219-221.

[44] Barboule N, Chadebech P, Baldin V, Vidal S, Valette A. Involvement of p21 in mitotic exit after paclitaxel treatment in MCF-7 breast adenocarcinoma cell line. Oncogene, 1997, 15: 2867-2875.

[45] Gibb RK, Taylor DD, Wan T, O'Connor DM, Doering DL, Gercel-Taylor C. Apoptosis as a measure of 
chemosensitivity to cisplatin and taxol therapy in ovarian cancer cell lines. Gynecol. Oncol. 1997, 65: 13-22.

[46] Blajeski AL, Kottke TJ, Kaufmann SH. A multistep model for paclitaxel-induced apoptosis in human breast cancer cell lines. Exp. Cell Res. 2001, 270: 277-288.
Copyright $₫ 2014$ Mukta Bagul, Srikanth Kakumanu, Thomas A. Wilson. This is an open-access article distributed under the terms of the Creative Commons Attribution License, which permits unrestricted use, distribution, and reproduction in any medium, provided the original author and source are credited. 